\title{
Francisco Alves da Silva Castilho: um professor na invenção da Escola Brasileira oitocentista
}

Francisco Alves da Silva Castilho: a teacher in the invention of the 19th century Brazilian School

Francisco Alves da Silva Castilho: un maestro en la invención de la escuela brasileña del siglo XIX

\author{
Angélica Borges \\ Universidade do Estado do Rio de Janeiro (Brasil) \\ http://orcid.org/0000-0003-0207-943X \\ http://lattes.cnpq.br/8302434402212876 \\ angelicaborgesrj@gmail.com \\ Giselle Baptista Teixeira \\ Prefeitura Municipal de Duque de Caxias (Brasil) \\ http://orcid.org/0000-0001-7264-2908 \\ http://lattes.cnpq.br/3077160513014383 \\ gizt2000@yahoo.com.br
}

\section{Resumo}

Neste artigo analisamos aspectos da trajetória de um professor público primário da Corte, Francisco Alves da Silva Castilho, que lecionou por aproximadamente 38 anos (1849-1887), com intuito de propiciar uma reflexão acerca dos diferentes papéis desempenhados pela docência na invenção da "Escola brasileira" Oitocentista e do próprio magistério. Castilho tornou-se autor de livros, escreveu em periódicos, participou de Conferências Pedagógicas e de associações que indicam diferentes modos de inserção na sociedade. $\mathrm{O}$ estudo usa as contribuições de Antonio Nóvoa, Escolano Benito e Edward Thompson no que se refere ao processo de profissionalização docente; à configuração da história escolar e do magistério; e ao conceito de experiência, para se pensar a constituição da trajetória docente. A investigação utilizou documentos manuscritos do Arquivo Geral da Cidade do Rio de Janeiro, relatórios da Inspetoria Geral de Instrução, manuais escolares e periódicos localizados na Biblioteca Nacional.

Palavras-chave: Profissão docente. Instrução primária. Brasil Império. 


\begin{abstract}
In this article we analyze aspects of the trajectory of a court primary public teacher, Francisco Alves da Silva Castilho, who taught for approximately 38 years (1849-1887), in order to provide a reflection on the different roles played by teaching in the invention of the Brazilian school, from the nineteenth century, and the teaching profession. Castilho became the author of books, wrote in periodicals, participated in Pedagogical Conferences and associations that indicate different ways of insertion in society. The study uses the contributions of Antonio Nóvoa, Escolano Benito and Edward Thompson with regard to the process of teaching professionalization; the configuration of school history and teaching; and the concept of experience, to think about the constitution of the teaching trajectory. The investigation used handwritten documents from the Rio de Janeiro City General Archive, reports from the General Inspectorate of Education, textbooks and periodicals located at the National Library of Brazil.
\end{abstract}

Keywords: Teaching profession. Primary education. Brazil Empire.

\title{
Resumen
}

En este artículo analizamos aspectos de la trayectoria de un maestro público primario de la corte, Francisco Alves da Silva Castilho, que enseñó durante aproximadamente 38 años (18491887), con el fin de proporcionar una reflexión sobre los diferentes roles que desempeña la enseñanza en la invención de la "Escuela" siglo XVIII y la profesión docente en sí. Castilho se convirtió en autor de libros, escribió en publicaciones periódicas, participó en conferencias y asociaciones pedagógicas que indican diferentes formas de inserción en la sociedad. El estudio utiliza las contribuciones de Antonio Nóvoa, Escolano Benito y Edward Thompson con respecto al proceso de profesionalización docente; la configuración de la historia escolar y la enseñanza; y el concepto de experiencia, para pensar en la constitución de la trayectoria docente. La investigación utilizó documentos escritos a mano del Archivo General de la Ciudad de Río de Janeiro, informes de la Inspección General de Educación, libros de texto y publicaciones periódicas ubicados en la Biblioteca Nacional.

Palabras clave: Profesión docente. Educación primaria. Imperio de Brasil. 
A escola por este modo organizada é uma pequena sociedade...

(CASTILHO, Escola Brasileira, 1859, p.21)

\section{Introdução}

A docência constitui uma ocupação intimamente relacionada aos projetos de civilização, progresso e ordenação de sociedades no século XIX. Apesar dos efeitos da regulação normatizadora do ofício que incidiam em torno da formação, seleção e exercício docente, cabe considerar as diversidades regionais, as culturas escolares e experiências docentes que conferiram diferentes matizes aos processos de constituição da profissão (MUNHOZ; BORGES, 2018). Nesse sentido, investigar as trajetórias de professores contribui para compreender os complexos tensionamentos que atuam na configuração do ofício e da escola, entendendo trajetória, conforme assinalado por Vidal (2010), como um conjunto de experiências acumuladas pelo professor ao longo de sua vida.

Dessa forma, neste estudo pretendemos analisar aspectos da trajetória e da obra de um professor público primário da Corte, Francisco Alves da Silva Castilho, que lecionou por aproximadamente 38 anos (1849-1887) na mesma escola. Castilho tornou-se autor de livros, escreveu em periódicos, participou de Conferências Pedagógicas e de associações que indicam diferentes modos de inserção na sociedade, e, ao final da carreira, foi nomeado delegado da instrução. Um professor que também procurou exercer o direito de pensar diferente e de problematizar os comandos que recebia. Dessa forma, o intuito é refletir acerca dos diferentes papéis desempenhados pela docência na invenção da "Escola brasileira" Oitocentista e do próprio magistério.

Para produzir a análise, operamos com as contribuições de Nóvoa (1991) no que diz respeito ao processo de profissionalização docente; com as reflexões de Escolano Benito (2011) ao compreender que a história da escola e da profissão docente são marcadas por acomodações, traduções, apropriações e resistências e pelo modo como os atores do magistério constroem um protagonismo social e cultural; e com o conceito de experiência de Thompson (1981) a fim de considerar as experiências individuais e coletivas docentes produzidas no jogo das tensões sociais.

A investigação foi realizada a partir de documentos manuscritos do Arquivo Geral da Cidade do Rio de Janeiro (ACGRJ), relatórios da Inspetoria Geral de Instrução Primária e Secundária da Corte (IGIPSC), manuais escolares localizados na Biblioteca Nacional e periódicos da época da Hemeroteca Digital da Biblioteca Nacional. O estudo está organizado em dois movimentos. No primeiro realizamos uma análise da trajetória do professor enfatizando sua atuação na escola, na imprensa e na sociedade. No segundo, apresentamos uma reflexão acerca da sua produção de livros escolares e métodos de ensino, entre os quais a "Escola brasileira" que ajuda a compor o título deste artigo.

\section{O lugar do exercício docente: a escola pública na freguesia de Campo Grande}

Natural da freguesia de Nossa Senhora do Desterro de Campo Grande, situada no município da Corte, capital do Império, Francisco Alves da Silva Castilho foi nomeado para escola pública primária do sexo masculino da freguesia de Campo Grande, em 5/02/1849, permanecendo no cargo até a jubilação em 12/02/1887, contabilizando, portanto, 38 anos de magistério.

Castilho, de acordo com Schueler, fez parte de um conjunto de professores que apresentaram uma produção intelectual e didática contribuindo para a "constituição da cultura escolar, dos campos de saberes e práticas pedagógicas" (2005a, p.1). Em sua pesquisa, a autora pode perceber como professores pertencentes a um grupo de intelectuais 
da segunda metade do século XIX, "mantiveram uma participação ativa no cenário educacional da época, atuando também como autores de livros e materiais didáticos e participando de diversas modalidades de produção escrita, como memórias, relatórios sobre escolas e práticas, cartas, correspondências, petições, crônicas, prosa e poesias, entre outros." (SCHUELER; SILVA, 2006, p.6127).

Para Castilho participar das atividades no centro da Corte tinha que fazer um longo percurso. Campo Grande era uma freguesia rural, o que significava, entre outras coisas, dificuldade de deslocamento e uma diferença salarial no exercício do ofício docente. $\mathrm{O}$ salário do professor público era menor nas áreas rurais. Mas Castilho também lecionava no ensino particular, conforme aponta um estudo que recobre o período de 1860 a 1889 e que assinala que a atuação em escolas e colégios particulares na condição de professores, diretores e/ou proprietários não era algo incomum entre os professores públicos (SCHUELER; SILVA, 2006, p.6127). Schueler também aborda a existência de outras atividades profissionais exercidas pelos professores e traz o exemplo do próprio professor Castilho: "Reconhecido pela autoria de compêndios e cartilhas escolares, ele foi denunciado por se dedicar mais à agricultura em seu sítio, situado na mesma localidade, que propriamente às suas atividades no ensino" (SCHUELER, 2002, p. 179). A acusação vai ao encontro da concepção de que o professor deve se dedicar exclusivamente ao magistério, o que se tornará uma norma prevista nas leis e mais um mecanismo para regular a profissionalização da docência, processo histórico de constituição da profissão a partir de mecanismos de formação, recrutamento e regulação (SCHUELER, 2002; NÓVOA, 1991).

De acordo com o Regulamento da Instrução da Corte de 1854, cada freguesia da cidade deveria ter seus estabelecimentos de ensino fiscalizados por um delegado da instrução nomeado pelo governo. Por meio dos documentos produzidos neste serviço é possível perceber o funcionamento das escolas e aspectos da realidade local ${ }^{1}$. O delegado responsável por fiscalizar a freguesia de Campo de Grande era o médico Eugênio Carlos de Paiva que ocupou o cargo por 28 anos, tarefa interrompida pelo seu falecimento.

Foi possível localizar um conjunto de documentos que apontam a preocupação da Inspetoria Geral de Instrução Primária e Secundária da Corte (IGIPSC) com a frequência na escola de Campo Grande. Em resposta a uma solicitação do inspetor geral, o delegado Eugenio que passava frequentemente em frente à escola, por ser caminho para seu trabalho, também recorreu ao testemunho da Igreja para comprovar que o estabelecimento funcionava diariamente:

como médico nesta freguesia muitas vezes passo pela frente da Escola publica, e ainda não encontrei uma só vez a porta da mesma fechada em dias úteis, além daqueles que tenho mencionado por atestados mensais. O vizinho mais próximo ao estabelecimento público é o vigário da Freguesia, pessoa muito capaz e digna de fé e respeito: esse afirma também a assiduidade do professor (AGCRJ, Códice 11.1.4, 15/02/1857, f.31).

Em outro documento, o delegado atribuiu a baixa frequência a dois problemas: "distância em que se acha a Escola, dos diversos lugares da Freguesia: o pequeno número de meninos no recinto da mesma, e a muito pouca vontade ou antes a repugnância que tem os habitantes deste Distrito em matricular os meninos na Escola pública” (AGCRJ, Códice 11.1.4, 25/10/1857, f.53).

\footnotetext{
${ }^{1}$ Durante o procedimento de visita, o professor é submetido ao olhar da inspeção, que produz saberes acerca da escola e da docência, inscrevendo-os em uma zona de visibilidade por meio da documentação produzida pelo delegado para ser remetida aos superiores. Tais saberes associados ao exercício da escrita compunham uma documentação diversificada, formada por cartas, ofícios, requerimentos e outros tipos de documentos (BORGES, 2008).
} 
A repugnância que o médico alega terem os habitantes integra o discurso que culpabiliza a família pela ignorância dos filhos e que pretende retirar dela o papel de educar em favorecimento da escolarização. De acordo com Cunha (2000), a instituição familiar que "era caracterizada como em permanente estado de mal funcionamento, era dada como incompetente, incapaz, sem qualidades para educar as crianças" (2000, p.452-453). No combate para inserir as famílias nos padrões de normalidade, uma das frentes era a escola, principalmente os internatos com rígidos padrões de moralidade e higiene (CUNHA, 2000). O discurso em torno da incompetência da família também pode ser visto em documento do professor Castilho. Ao apresentar à IGIPSC um método de ensino de sua autoria, Castilho menciona a existência de um menino pobre cuja família não era "amante da instrução", mas que havia aprendido rápido com o referido método que estava em discussão na inspetoria ${ }^{2}$. A ideia da necessidade da família zelar pela educação dos filhos também aparece em uma obra de Castilho destinada à educação moral e religiosa, assim como problema da frequência irregular dos alunos, conforme abordaremos adiante.

Embora a localização da escola na qual lecionou por 38 anos estivesse situada em uma freguesia rural, distante da sede da IGIPSC, localizada, na então chamada Rua do Ourives, no centro da cidade, houve uma significativa troca de ofícios entre a repartição de inspeção e o professor, conforme podemos observar por meio da documentação guardada no AGCRJ, bem como um envolvimento com questões relacionadas à ação da inspetoria, ao movimento dos professores e à imprensa pedagógica. Sinal do esforço do professor em expor suas ideias e participar ativamente das discussões em torno da instrução e que estavam na pauta pedagógica da época. Igualmente demonstra o exercício de construir por meio da prática docente um protagonismo social e cultural (ESCOLANO BENITO, 2011).

\section{"Ditado pelo entusiasmo na atualidade": participação em debates educacionais e inserção na sociedade}

A atuação do professor Castilho pode ser observada por meio de ofícios trocados com a IGIPSC, nos escritos produzidos para imprensa pedagógica, nos debates que se deram nas Conferências Pedagógicas e nos jornais da época. No caso dos documentos de sua autoria, sua escrita parece adquirir matizes diferenciadas, de acordo com o período em que escreve, a função e o destinatário de seu discurso. $\mathrm{O}$ tom e a eloquência dependiam do objetivo a ser alcançado pelo professor, como uma aprovação de método ou de compêndio, reivindicação, questionamento ou reclamação, e, igualmente, do público ou indivíduo ao qual se destina, ou seja, o inspetor, o governo, os colegas professores, o leitor de periódico. Estratégias de escrita diversificadas para cada situação, como recomenda os manuais de civilidade da época, como o chamado Código do Bom Tom do cônego Roquette, publicado em 1845.

Em 1856, ao dedicar ao inspetor geral dois métodos de sua autoria chamados de "Escola brasileira", produziu um documento de duas páginas, por meio do qual expõe suas ideias a respeito do Regulamento de Instrução Primária e Secundária da Corte de 1854:

Com a brilhante aurora que vem esclarecendo toda a circunferência do nosso horizonte, o progresso vai aparecendo em todos os ramos da Administração pública como as flores do alvorecer de um dia luminoso. A instrução pública será o Astro deste grande dia; e o seu resplendor iluminará a face mudada do nosso solo. Desculpe-me V.Ex. este preâmbulo ditado pelo meu entusiasmo na atualidade. Jaziam os professores de primeiras letras em um letal desanimo pelo critico estado

\footnotetext{
${ }^{2}$ AGCRJ, códice 10.4.38, 26/09/1856, p.31 e 20/11/1856, p. 34.
} 


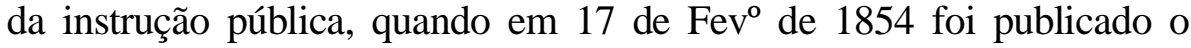
Regulamento para a reforma do ensino primário e secundário do Município da Corte. O município saudou a esta Pomba que entraria o feliz anúncio de uma nova era, e os professores públicos soltarão um longo suspiro desafogando o peito para receber uma doce esperança de vida. Porém a demora da execução desta Lei, os embaraços que se opposerão a que os actuaes Professores entrassem a gozar das vantagens que se lhes ofereciam pelo dito Regulamento, [palavra não identificada] necessitam gravemente que a Instrução publica não sairia já tão cedo desse estado de crônica e talvez incurável apatia, se V.Exa chamado para ser Inspetor Geral, lhe não acudir-se com tanta prontidão e solicitude. [...] porém como membros desta classe que hoje se distingue pelo nome prestigioso de V.Ex ${ }^{a}$ que, qual outro gerando [?], tanto zelo e tanta affeição mostra e ella, os professores de primeiras lettras considerão-se tão penhorado pelos serviços que V.Ex tem prestado a Instrução Publica que se julgarião desempenhados se pudessem exigir um Arco triumphal para assinalar o seo enthuasiasmo nesta época da Administração de V.Exa . Este monumento deveria ser então um systema de ensino inteiramente [?] nacional, isto é adaptado as circunstancias especiaes do Paiz, seria a nacionalização do ensino tanto no methodo como na Doutrina. Porem desta obra de V.Ex $x^{a}$ poderá ser o Architeto e nós não poderíamos trabalhar nella senão como meros obreiros, embora animados da maior boa vontade. Pela minha parte, sou o mais insignificante dos membros deste corpo mas nem por isso me corre pelas veias um sangue menos quente do que aquelle que anima a todo os meus companheiros. Bem que na [palavra não identificada] e força das cristas de V.Ex. trabalho, todavia, dominado pelo mesmo sentimento prova não desmerecer a honra que V.Ex prodigalisa toda a classe: e cheio de reconhecimento peço a V.Ex licença para dedicar lhe as premissas de meu trabalho. São dous methodos de ensinar a ler, que sob o titulo Escola Brasileira que deve comprehender todas as obras do ensino elementar, tenho organisado, sendo um para o ensino de meninos, e outro conjunto especialmente para adultos, podendo ser empregado também aos meninos de mais desenvolvida inteligência. Se esta obra puder satisfazer ao fim a que é destinada, tornando-se então digna da Pessoa a que é dedicada, espero que V.Ex receba como uma pequena homenagem de minha parte, em desconto de grande divida em que se acha empenhada para com V.Ex toda a classe dos Professores públicos de Primeiras lettras do Município da Corte (Códice 10.4.38, 25/06/1856, fs.19-20).

A citação é grande, mas nos permite vislumbrar aspectos importantes do debate da época. Nota-se que Castilho fez suas observações como se estivesse representando a classe dos professores da Corte, representação que foi motivo de disputa na corporação docente, na segunda metade do século XIX ${ }^{3}$ (VILLELA, 2002; SCHUELER, 2002; LEMOS, 2006). Proferiu elogios ao Regulamento de 1854 que teria surgido como uma "brilhante aurora" que veio animar os professores em situação de "letal" desânimo. No entanto, alega não bastar a existência da lei, era

\footnotetext{
${ }^{3}$ A disputa pela legitimidade de representação da corporação dos professores pode ser vista, por exemplo, por meio da imprensa pedagógica em que "dois jornais ["A Instrução Pública” e a "A Verdadeira Instrução Pública"] disputavam o direito a essa representação e, mais do que isso, disputavam a construção da imagem do professorado, produzindo discursos, construindo visões e representações do ser professor, dos papéis e condutas que estavam sendo delineados" (LEMOS, 2006, p.75).
} 
preciso alguém que acudisse a classe com solicitude. Eis que o Ministro Couto Ferraz nomeia Eusébio de Queiroz como inspetor geral, um dos cardeais do grupo conservador fluminense, denominado de Saquaremas (MATTOS, 2004). Com uma linguagem laudatória, o professor realiza uma reflexão acerca da política voltada para o magistério e expressa seu entusiasmo com a administração de Eusébio. O "arco triunfal" viria com um sistema de ensino, tanto com o método como na doutrina, de caráter nacional. Com a explanação de tais ideias introduz o seu oferecimento, iniciado com a humildade de um "insignificante", como aconselha as regras de civilidade, de seus dois métodos de leitura, que se encaixam de forma oportuna no ideal de um sistema de ensino adaptado à realidade brasileira defendida pelo professor.

No entanto, em documento de 4/09/1856 (AGCRJ, Códice 10.4.38, f.35), observamos Castilho, em uma ação de resistência, entre tantas que constituem a história da escola, conforme assinala Escolano Benito (2011) rebatendo as críticas presentes no relatório do inspetor Eusébio de Queiroz, referente ao ano de 1855. Apesar da sua admiração pelo inspetor, o professor não se inibiu na tarefa de contestar. No início do ofício, o professor reclamou da casa da escola e pediu a construção de um edifício adequado. Relatou ter lido no "ilustrado relatório" que Eusébio, ao comparar a frequência das escolas entre as freguesias, sugere não ver necessidade da escola de Campo Grande continuar funcionando e onerando os cofres públicos. O motivo seria a "improficuidade" da escola, atribuída ao diminuto número de alunos. Diante do relato do inspetor, o professor contra-argumentou que a escola era a única da região, situada em um lugar chamado Mendanha, para o qual foi removida por ter sido considerado o mais conveniente. Alegou que é frequentada por crescido número de alunos, até mais do que em outras freguesias da cidade, e apontou como prova os mapas de frequência de 1849 a 1853, ano em que foi ordenada a mudança para o referido lugar.

O professor Castilho atribuía a baixa frequência à grande distância que os meninos pobres precisavam percorrer para chegar à escola e ao regime de duas sessões que os obrigavam a fazer quatro viagens a pé. Diante da situação, os alunos acabavam não retornando para a aula da tarde. O professor já havia solicitado meses antes ao inspetor "que se digne a remover da minha escola os embaraços e os inconvenientes que resultam da execução do art. 22 do Regimento Interno" (Códice 10.4.38, 31/01/1856, f.14). O artigo 22 determinava que a escola deveria funcionar em dois turnos. No verão, das $8 \mathrm{~h}$ às $11 \mathrm{~h}$ da manhã. No inverno das 8h30 min as 11h30min. Já as aulas de tarde seriam sempre das 3h às 5h30min. Tal organização das aulas era muito criticada pelos professores, principalmente, os que atuavam nas freguesias distantes do centro da Corte e também motivou a escrita de abaixo-assinado pelos pais dos alunos que solicitavam a alteração dos horários.

Castilho também apontou uma solução já conhecida e sugerida por muitos professores e, igualmente, indicada pelo regulamento: "Portanto sendo o meu fim único prevenir V.Ex. sobre a necessidade de casa para a escola, que não pode dispensar esta freguesia, onde pelo contrário só o internato poderia satisfazer as necessidades do lugar, dou concluído este ofício". (Códice 10.4.38, 31/01/1856, f.14)

Juntamente ao problema da distância e do regime de duas sessões de aula, o professor coloca outro aspecto que, segundo ele, contribui para a baixa frequência: a exigência da vacinação dos alunos para matrícula nas escolas, conforme estabelece o artigo 69 do regulamento de 1854. A exigência foi alvo de debates envolvendo professores, delegados e o inspetor geral. Castilho, em ofício dirigido ao inspetor geral, expõe que:

Allem da causa sobredicta pode ser também que algumas exigências do Regulamento de 17 de fevereiro por mal interpretadas tenhão aqui concorrido innocentemente para afastar hoje a freqüência da escola, pois na verdade muitos pais só por não vacinarem seos filhos preferem deixálos na ignorância ficando neste ponto contrariada a mente do legislador 
quando entendeo que o interesse da instrucção faria com que os pais tratassem com mais diligencia de acautelarem a vida de seus filhos exposta ao terrível mal das bexigas (códice 10.4.38, 4/09/1856, f.35).

No documento enviado por Castilho pode ser observada uma anotação à parte, feita após a entrega na IGIPSC, que diz que "também já se notou que a exigência da vacina tem sido motivo de dificuldade para frequência" e que por isso parece conveniente propagar a vacinação e "permitir que se relaxe a execução dessa disposição, pois é aumentar a aflição ao aflito fazêlo sofrer" (AGCRJ, Códice 10.4.38, 4/09/1856, p.35). Embora não possua assinatura é possível que seja de autoria do inspetor geral, concordando com o problema e deixando registradas algumas soluções como a de relaxar a execução da norma.

Anos depois, na década de 1860, Castilho aparece como membro da Academia Pedagógica que foi instalada com "o fim de estudar a pedagogia e todas as matérias relativas ao ensino primário" (CORREIO MERCANTIL e O CORREIO DA TARDE, 26/07/1860). $\mathrm{Na}$ Academia, os professores se organizaram em duas comissões de estudos: uma para estudar teoria do ensino, formada por Francisco Alves da Silva Castilho juntamente com os professores Candido Matheus de Faria Pardal e Joaquim Sabino Pinto Ribeiro; outra para estudar prática de ensino. Castilho fazia parte da comissão de estatuto, indicando que também estava à frente da organização dessa instituição.

Esse movimento docente se acentua nas décadas de 1870 e 1880 que, segundo Martinez (1998), foi um período marcado por tensões e embates nos quais a instrução e a educação da população foram intensamente discutidas, em razão das transformações sóciopolíticas, econômicas e culturais da época. Cabe lembrar que, em 1871, os professores escreveram o Manifesto dos Professores Públicos da Instrução Primária da Corte endereçado ao Imperador e ao Ministro do Império, no qual denunciaram a situação precária em que trabalhavam (LEMOS, 2006). Nesse sentido, a escrita e as colocações de Castilho também vão acompanhar o calor dos debates.

Nesse momento, foram organizadas as Conferências Pedagógicas, das quais Castilho, que acumulava uma experiência de mais de 20 anos no magistério, participou ativamente. As conferências se constituíram como um dispositivo de modelação e de formação docente, imposto pelo governo imperial, tendo em vista que a presença dos professores públicos era obrigatória e aqueles que não justificassem ausência seriam punidos com a perda de gratificações ${ }^{4}$. As Conferências funcionavam como uma estratégia para assegurar a homogeneização da classe docente, tendo em vista a busca de um modelo ideal de professor. No entanto, também instauraram um espaço que proporcionou o encontro de professores e contribuiu com as discussões em torno de questões educacionais (BORGES; GONDRA, 2005). Em um relatório do Inspetor Geral Homem de Mello acerca da primeira Conferência, consta que após o conselho diretor examinar os trabalhos produzidos foram declarados "dignos de distinção, revelando estudo, zelo e dedicação no desempenho de suas funções no magistério primário" vários professores, entre os quais Francisco Alves da Silva Castilho. Entre os nove professores listados ${ }^{5}$, três eram ligados à organização do periódico "A Instrução Pública": Costa e Cunha, Cony e Castilho.

\footnotetext{
${ }^{4}$ No Brasil, as conferências pedagógicas foram estabelecidas pelo decreto n. 1331, de 17 de fevereiro de 1854, que regulamentou a instrução primária e secundária do Município da Corte. Porém, apenas em 1872 o governo organizou as instruções especiais, previstas pelo decreto n.1331, para regular as conferências, que vieram a ocorrer em 1873. A partir de então, elas foram realizadas com frequência irregular até o final da década de 1880 (BORGES; GONDRA, 2005).

${ }^{5}$ Antonio Estevão da Costa e Cunha, Antônio Ignácio de Mesquita, Antônio José Marques, Augusto Cândido Xavier Cony, Cândido Matheus de Faria Pardal, Francisco Alves da Silva Castilho, Gustavo Alberto, Olympio Catão Viriato Montez e Phillipe de Barros.
} 
As sessões do periódico "A instrução Pública", segundo Villela, tratavam de "atos legais e legislação do ensino, apresentavam questões metodológicas e assuntos de interesse geral como economia, fisiologia do corpo humano, textos literários e de fundo moral ou religioso, poesias, questões gramaticais, matemáticas, charadas, noticiários" (2000, p.129). A autora destaca que a partir dos editoriais deste periódico teve início uma verdadeira polêmica entre professores que culminou na criação de outro jornal, chamado "A verdadeira Instrução Pública", indicando, já pelo título, o seu caráter de oposição ao primeiro, acusado de ser ligado ao governo.

Ao longo do exercício do magistério, a relação do professor Francisco Alves da Silva Castilho com os diferentes sujeitos que estiveram na posição de governo foi caracterizada por adesões, mas também por questionamentos e críticas. Assim compreende-se a atuação dele junto a um jornal pedagógico ligado ao governo e sua resposta às críticas feitas ao magistério pelos ministros do império que reclamavam da ausência de formação pedagógica dos mestres-escolas (Schueler, 2005b). Segundo Schueler, Castilho entendia que a questão era um problema de disputas, em que professores e governo acusavam-se mutuamente pelas causas do atraso na instrução:

E o governo, muito naturalmente, 'acreditando já ter se esforçado', colocava na atuação e nas pessoas dos mestres - a suposta falta de métodos modernos de ensino - a culpa pelo fracasso escolar na cidade. Também, igualmente de forma natural, dizia Castilho, os professores, na lida do seu cotidiano de trabalho, apontavam ao governo outras causas para que o progresso da instrução pública estivesse desgastado. A principal delas era óbvia: a deficiência da remuneração pecuniária, nas palavras textuais do mestre (2005b, p.385, grifos no original).

Diante das críticas, torna-se interessante destacar que Castilho, após ser jubilado do magistério, tornou-se delegado de instrução da freguesia de Campo Grande. A nomeação indica que sua atuação e experiência no campo da docência, na autoria de compêndios e de métodos de ensino, bem como as reflexões que produziu ao longo da carreira, podem ter lhe conferido um estatuto favorável a um determinado modelo de docência e de inspeção almejado pelo governo. Detentor de conhecimentos pedagógicos, Castilho poderia exercer uma fiscalização mais eficaz, com caráter educativo, como desejavam os conservadores e inspetores Eusébio de Queiroz e Bandeira Filho, quando afirmaram que os delegados, investidos de um determinado saber, poderiam guiar os professores "no desempenho dos seus deveres, aconselhal-os sobre a pratica do ensino, corrigir os seus defeitos, animar a sua dedicação, e applaudir os seus bem succedidos esforços" (Relatório da IGIPSC de 1883, p. 10).

No que se refere a outros modos de inserção na sociedade, cabe destacar que seu nome figura como fundador do Instituto Philarmonico da Freguesia de Campo Grande (O APÓSTOLO, 13/02/1870, p.56) e como membro da Sociedade Beneficente e Propagadora dos direitos dos cidadãos da freguesia de Campo Grande. No discurso de inauguração do Instituto Philarmonico, Castilho afirma que "a vida precisa de gozos", mas não os gozos de "deleite do corpo" e sim "nas recreações do espírito e na satisfação das necessidades morais que constitui o gozo da alma e contentamento do coração" (O APÓSTOLO, 27/02/1870, p. 71). Por isso, o Instituto tinha a finalidade "de obter cantores para os exercícios religiosos da nossa igreja matriz e ao mesmo tempo instrumentistas para os recreios familiares" (O APÓSTOLO, 27/02/1870, p. 72). Também tratou da importância dos "laços de união social", alegando que o "gênero humano degenera e embrutece fugindo da sociedade para o isolamento" (O APÓSTOLO, 27/02/1870, p. 71). Em razão disso defende que se reunissem com maior frequência no Instituto para evitar os males do isolamento. 
A outra instituição na qual Castilho atuou, Sociedade Beneficente e Propagadora dos direitos dos cidadãos da freguesia de Campo Grande, chama bastante atenção pelo próprio nome. Uma nota do jornal Correio da Tarde, ao tratar das primeiras ações, já aponta as intrigas entre estas associações e a política local. A nota parecia ter a intenção de provar a veracidade dos objetivos da sociedade e da atuação do grupo - "tapar a boca da maledicência ou fazer emudecer aos incrédulos" - frente à descrença em torno destas instituições que estariam ligadas às desgraças dos "desfavorecidos da fortuna", ocasionadas pelo "inocente exercício do mais importante dos seus direitos constitucionais, isto é, o de votar nas eleições primárias" (CORREIO DA TARDE, 28/01/1860, p.2). Observa-se que a concepção de "direitos dos cidadãos" aparece diretamente relacionada ao direito de votar. Mattos assinala que a Constituição de 1824, ao reconhecer os direitos civis dos cidadãos brasileiros, diferenciou-os em função de suas posses por meio do voto censitário em três gradações: "o cidadão passivo (sem renda suficiente para ter direito a voto), o cidadão ativo votante (com renda suficiente para escolher, através do voto, o colégio de eleitores), e o cidadão ativo eleitor e elegível" (2000, p.20-21). A palavra "propagadora" que compõe o nome da sociedade poderia sugerir a ideia de ajudar os "cidadãos passivos" a se tornarem ativos por meio dos auxílios fornecidos pela instituição. Assim compreendem-se as razões pelas quais os críticos acusavam essas associações de serem movidas por interesses eleitoreiros.

No entanto, entre os exemplos usados para comprovação de que a Sociedade Propagadora seguia seus estatutos, "ocupando-se com negócios importantes em benefício da freguesia", consta a ajuda aos enfermos, a entrega de esmolas e a proposta do professor Castilho acerca da necessidade de abertura de escolas particulares nos pontos da freguesia que estavam fora do alcance da escola pública:

Esta proposta, que foi acolhida com geral aplauso, tem por objetivo uma representação promovida pela sociedade, pedindo ao governo medidas que facilitem o ensino particular nos pontos afastados da escola pública a todos que puderem dar à mocidade os elementos mais indispensáveis da instrução pública (CORREIO DA TARDE, 28/01/1860, p.2).

Embora o texto não informe as medidas reivindicadas, é possível inferir que ela se desse por meio da subvenção de escolas particulares para o ensino de crianças pobres. O professor também ofereceu à Sociedade seus serviços em benefício da instrução de adultos. A presença de um professor como sócio da instituição, que fazia propostas para melhorar o ensino na localidade, corroborava a legitimação das atividades da Sociedade - que também poderia ser usar a instrução como meio para "propagar direitos dos cidadãos" da freguesia -, bem como fortalecia o nome de Castilho como eleitor ${ }^{6}$ pela freguesia de Campo Grande, como ocorreu em 1861, no ano seguinte ao da fundação da Sociedade (DIÁRIO DO RIO DE JANEIRO, 12/01/1861). Em nota publicada em jornal de grande circulação (CORREIO MERCANTIL, 27/01/1861, p.2), Castilho agradece aos "comparoquianos" e amigos que se empenharam na sua eleição, demonstrando que havia uma rede de relações que lhe permitiu sustentar uma candidatura a eleitor na freguesia rural onde residia e trabalhava como professor.

\section{A produção de livros: o método de leitura e o catecismo de Castilho}

Assim como o método "Bacadafá"7 de Antonio Pinheiro de Aguiar, o método de leitura de Francisco Alves da Silva Castilho, denominado "Escola Brasileira", também se destacou nas páginas dos relatórios dos Ministros do Império e da Inspetoria, com as notícias do seu ensaio realizado na escola pública da freguesia de Campo Grande.

\footnotetext{
${ }^{6}$ A Constituição de 1824 estabeleceu a idade mínima de 25 anos (21 para casados, militares, clérigos e bacharéis) e instituiu o critério de renda mínima anual de 100 mil réis por ano para ser votante e 200 mil para ser eleitor. A partir da reforma de 1846 o cálculo passou a ser em prata, o que equivalia ao dobro desses valores.

${ }^{7}$ Para saber mais sobre o método de leitura Bacadafá, consultar Schueler (2002) e Teixeira (2008).
} 
Ao longo de sua carreira na profissão docente, Castilho também se tornou autor de livros, tendo publicado as seguintes obras: "Methodo para o ensino rapido e aprazivel de ler impresso, manuscripto e numeração, e descrever", em 1850; "Methodo de leitura para o ensino dos meninos e adultos", em 1863; "ABC de amor, ou methodo ameno de ensinar as moças, conforme o systema da Escola brasileira", "Preliminares de grammatica", e "Grammatica pittoresca ou systema grammatical explicado pela arvore da sciencia", de 1864; "O principio da sabedoria é o temor de Deos", em 1872; e o "Manual explicativo do methodo de leitura denominado Escola brasileira" em 1859, sendo este último o objeto da presente análise.

No relatório do Ministro do Império do ano de 1857, há a notícia do ensaio do método elaborado por Castilho, trazendo as seguintes informações ${ }^{8}$ :

Continúa a ser seguida nas escolas o mesmo methodo e systema de ensino prescripto pelo regulamento. Os ensaios do methodo de leitura do professor publico da freguezia de Campo Grande, Francisco Alves da Silva Castilho, a que sob immediata direcção do autor se tem procedido, desde o anno próximo passado, nas escolas de Santa Rita, Candelária e ultimamente em uma sala particular para esse fim alfaíada, não produzirão ainda resultados bastante decisivos para autorisar sua adopção ou rejeição. Diz que julgou conveniente que antes de qualquer decisão definitiva admita-se em duas escolas exclusivamente regidas por ele, seguindo a marcha regular delas, e o aproveitamento anual dos respectivos alunos de experiência final e decisiva, parecendo esta medida tanto mais conveniente, quanto se os resultados então obtidos aconselharem a adoção geral do referido método, muito importará ter uma escola regida que ele sirva de norma e de modelo para a transição; a qual não sendo convenientemente preparada, poderia causar graves inconvenientes.

De acordo com o relatório, em 1857 delegou-se que o ensaio do método de Castilho fosse realizado em duas escolas regidas "exclusivamente" pelo autor, já que os ensaios anteriormente ocorridos em outras escolas, cujos professores apenas recebiam o auxílio de Castilho, não estariam produzindo os resultados necessários para sua adoção.

No ano de 1859, as informações trazidas em tais relatórios dão a notícia de que o referido método estava deixando de ser experimentado devido à falta da impressão, por parte do autor, dos exemplares necessários para a experiência final, evidência de que os custos da impressão eram financiados pelo próprio autor. De acordo com Schueler e Teixeira (2009), os professores interessados em ver seus métodos de ensino e textos publicados e referendados pelo governo passavam por grandes percalços, pois precisavam bancar os custos de impressão e edição, assim como deveriam comprovar a utilidade e a eficácia das inovações: "Experimentação com os alunos, exposição pública e avaliação pelos pares, professores públicos e demais autoridades consistiam em passos fundamentais para que um método ou um compêndio fosse adotado pelo governo" (SCHUELER; TEIXEIRA, 2009, p. 154).

De acordo com o dicionário de Sacramento Blake, o método composto por Castilho seria "um methodo novo e especial pela divisão e ordem dos elementos phonicos da palavra, e pela leitura imediata, independente de alphabetos e de syllabarios". Para Philippe da Motta d' Azevedo Corrêa, ele faria parte do "novo methodo de soletração", juntamente com os de "Valdetaro" e "Bacadafá". Segundo o próprio Castilho, em explicação dada na obra, seu método consistiria em:

uma modificação pouco importante do systema alphabetico, porém o seu merecimento, ou ao menos oque tal se me afigura, funda-se na applicação immediata, das letras (o que tambem não dou como cousa nova), e sobretudo no encadeamento

\footnotetext{
${ }^{8}$ Também é possível encontrar essa informação no códice 15.3.20, p. 72, que contém um ofício do Marques de Olinda ao Inspetor Geral Interino da Instrução Pública comunicando que o Conselho Diretor, a quem deu conhecimento do parecer da Comissão encarregada de estudos acerca do método de leitura do professor público da freguesia de Campo Grande Francisco Alves da Silva Castilho, bem como do processo, dos resultados e dos pormenores ocorridos durante a experiência, julgou conveniente a adoção exclusiva e interina do referido método em duas escolas públicas, cujos resultados comparados com os obtidos nas outras escolas, "habilitem a tomar uma decisão segura sobre sua adoção".

${ }^{9}$ Para saber mais sobre o método de Valdetaro, consultar Albuquerque (2019).
} 
de uma serie de lições fáceis e relativas a conhecimentos superiores, começando desde o ensino das letras até a leitura corrente, passando pela classificação, declinação e construção grammatical das palavras, porque este methodo, segundo o plano traçado, deveria ser a parte elementar do ensino da grammatica nas escolas; era isto uma reminiscência ainda do methodo de João de Barros ${ }^{10}$, que me passou pelos olhos na bibliotheca publica quando eu estudava grammatica. Esta primeira parte preparava $\mathrm{o}$ discípulo para um segundo tomo de leitura graduada o progresso da instrucção do discípulo, a fim de evitar na escola do ensino elementar a desigualdade de um degráo tão alto, como acontece com a transição que se faz da ultima carta que se acha no fim dos syllabarios mais communs por serem os mais baratos, e que os meninos the chamão nas escolas carta do meu amigo. Da qual saltáo logo pra o cathecismo ou para a leitura de fabulas (1859, p.8-9).

A obra aqui analisada foi localizada no setor de obras raras da Biblioteca Nacional. Datado de 1859, possui um total de 64 páginas. Publicado pela "Typographia de E \& H Laemmert, é oferecido à classe dos professores de primeiras letras. Segundo o próprio Castilho, era costume entre os autores buscarem um mecenas, que protegesse e recomendasse uma determinada obra, contudo, informa que achou melhor dirigir-se a seus colegas. Apesar deste aviso, Castilho acaba fazendo o mesmo, pois um dos pedidos feitos nessa dedicatória aos professores era que "em nome de nossa classe dedique eu o meu methodo de leitura ao Exmo. Sr. Conselheiro Eusébio de Queirós Coutinho Matoso Câmara, como uma franca homenagem, mas significativa amostra de nossa consideração, e reconhecimento dos serviços prestados á instrucção e á nossa classe" (1859, p.5).

Nesta apresentação, o professor também explica que, devido ao "Methodo Castilho - o Methodo portuguez"11 , do qual faziam-se ensaios, e à vinda de seu "ilustre autor" ao Rio de Janeiro para apresentá-lo e explicá-lo em sessões publicas, resolveu mudar o nome de seu trabalho "por outro mais sonoro e mais significativo - Escola Brasileira". Informa também que adotou este título com a intenção de que seus "collegas aceitando-o quizessem concorrer debaixo do mesmo nome com seus trabalhos para a organisação do systema de ensino, nacionalisando-o pelo methodo e pela doutrina" (1859, p.8). A opção de Castilho parece inserir-se efetivamente nas intenções de nacionalização das obras escolares em curso no período.

O autor alerta que "este methodo de ensinar a ler poderá não ser uma novidade, porém ao menos não o copiei eu de ninguém, e aquillo que por ventura aqui si possa encontrar de parecido com alguma cousa já existente será uma coincidencia que me não há de envergonhar como plagiário" $(1859$, p.9). Esta observação parecia ser uma resposta às possíveis críticas de plágio da obra de outro autor, talvez do próprio Castilho português, ou até mesmo às críticas que poderiam vir a surgir.

Castilho esclarece que seu método era dividido em parte "phonica" e parte "orthographica", e que dois eram os principais elementos que constituíam um método de ensino, o princípio lógico e o princípio prático. O primeiro consistiria na coordenação das ideias que se oferecem ao espírito de quem aprende. Já o segundo seria "um modo próprio de fazer colar no espírito do discípulo as idéas que se lhe quer transmitir". Elucida igualmente que seu método de leitura seria um "methodo syntheticoanalythico", que poderia ser praticado em qualquer dos modos conhecidos, e que o processo da parte elementar, se poderia dividir em dois períodos, que seriam:

$1^{\mathrm{o}}$ leitura; $2^{\mathrm{o}}$ escripta; que o primeiro periodo póde ainda ser subdividido em dous tempos, no ensino escolar: $1^{\circ}$ leitura collectiva nos semicírculos, $2^{\circ}$ leitura singular, isto é cada um em seu exemplar; finalmente póde dizer que o

\footnotetext{
${ }^{10}$ Um estudo sobre cartilha de João de Barros "Grammatica da Lingua Portuguesa com os mandamentos da Santa Madre Igreja" (1539) pode ser visto em Carvalho (2018).

${ }^{11}$ Método português destinado ao ensino da leitura e da escrita, elaborado por Antonio Feliciano de Castilho. Teve significativa repercussão no Brasil, sendo também ensaiado em escolas públicas, como nos informa o relatório do Ministro do Império do ano de 1857.
} 
processo deste methodo é compatível com a organisação de qualquer systemas no sentido pratico, porque no sentido lógico póde elle ser considerado com um systema, que por ora só comprehende a parte mais elementar da grammatica $(1859$, p.20).

Para Castilho, a aplicação de seu método demandaria uma disposição em que, primeiro, houvesse a organização da sala e do material da escola; segundo, a organização da classe; e terceiro, a organização do ensino. Sobre este último item, dizia:

Supponha-se a classe dividida nos dous grupos propostos (maior e menor), occupando cada grupo o lado que lhe foi designado (esquerdo ou direito); de sorte que a primeira divisão (leitura prolongada) occupe os primeiros bancos defronte de professor, seguindo-se em ordem graduada a segunda divisão (leitura natural), e por ultimo a terceira divisão (leitura corrente). Conviria talvez ao ensino que esta ordem fosse invertida, pela razão de ficarem mais perto do professor os discípulos que formão a sua turma, e mais distantes os que são dirigidos pelos monitores, porém, com os alumnos que formão a primeira divisão são em geral os mais pequenos e os mais novos da escola, estes precisão ser protegidos pela vizinhança do professor cada discípulo occupa seu lugar segundo o gráo de seu merecimento $(1859$, p.52).

Ao colocar que seu método poderia ser praticado com qualquer dos modos conhecidos, Castilho almejava uma maior aceitação por parte do professorado, já que, quando os professores não concordavam com as escolhas do governo, poderiam recorrer a outros métodos, como informa a Comissão de professores públicos de 1873. Nesse momento, conquistar os professores também poderia lhe trazer uma aceitação mais fácil por parte do governo imperial. Porém, ao mesmo tempo em que dizia que seu método poderia ser praticado com qualquer dos modos conhecidos, afirma que, para aplicação do mesmo, ou seja, para que se obtivesse os resultados esperados, seria necessário uma organização da sala, do material da escola e do ensino, designando a posição que cada grupo deveria ocupar.

Na organização pretendida por Castilho, podemos perceber a existência de determinados traços do ensino mútuo, com a divisão dos alunos em diferentes classes, de acordo com o nível de conhecimento e de merecimento, bem como a presença de monitores auxiliando os professores em suas aulas. Segundo Bastos (1999), o entusiasmo causado por este método residiria na facilidade de manter a disciplina que ele proporcionava, o que parecia ser uma preocupação central de Castilho, preocupação esta que pode ser entendida também como uma necessidade de afirmação de um modelo que o distinguisse dos demais.

Juntamente a certa preocupação com o controle, o autor prevê cada ação a ser desenvolvida pelos professores e monitores nos cinco tempos de aula, como é possível perceber pelo texto exposto na figura I. Tal descrição demonstra a intenção do controle exercido sobre a atuação dos professores, o que se torna contraditório com a primeira promessa da possibilidade de liberdade dos métodos. Contudo, o detalhamento das práticas a serem seguidas pelos professores e monitores, descritas em sua obra, pode ter agradado às autoridades governamentais, que almejavam o maior controle possível sobre os docentes, pois os livros de Castilho foram aprovados pelo governo imperial para utilização nas salas de aula ${ }^{12}$, informação esta trazida no relatório dos Ministros do Império e da Inspetoria do ano de 1877, no qual há uma lista dos "Professores públicos que têm escripto trabalhos didacticos".

12 Uma investigação acerca da produção, controle e circulação dos livros nas escolas da Corte Imperial pode ser visto em Teixeira (2008). 
Figura 1 - Cinco tempos de aula propostos por Castilho no ensino da leitura

$$
\text { Primeiro tempo (meia hora). }
$$

Inauguraçio do trabalho. -0 professor ou um monitor collocado junto ao estrado recitará em alta voz a oração do dia, que será repetida em córo por toda a classe. Segue-se a revista de asseio. Todo este trabalho, para o qual se dá o espaço de meia hora, póde ser concluido em muito menos tempo; neste caso o professor empregará o excedente no que melhor lhe parecer em proveito do ensino.

\section{Segundo tempo (meia hora).}

A prineira divisão, subdividida em turmas -.. $a, r, s, z$, $x, j, f, v$, etc. , dirigida cada uma pelo seu monitor, leráõ em semicireulo defronte dos quadros suspensos pelas paredes lateraes, em voz alta e prolongada, as palavras ou phrases da lição; as consoantes rapidas, embora não possão ser prolongadas, todavia as turmas prolongaráó a voz sobre a vogal com que ellas sôaro. Ora, como as vozes de todas as turmas a um tempo produzirião uma grande bulha e confusão, a leitura, nesta voz, será feita a córos seguidos e successivos, começando da primeira até á ultima turma, podendo ern cada uma ser preenchido o intervallo de uma a outra leitura pela cópia da letra em ardozia ou vidro fusco.

Segunda e terceira divisão. - Durante este tempo o professor determina as lições da terceira turma, que entra immediatamente em estudo; e o mesmo professor, ou adjunto se houver, ou os monitores, passaréó as liçoses á segunda divisão, explicando-as convenientemente.

\section{Terceiro tempo (meia hora).}

Primeira divisão. - Cada monitor conduzirá sua turma ao lugar que lhe compete nos bancos, e ahi leréó a mesma lição dous a dous nos quadros suspensos sobre as mesas, ou cada um em seu exemplar encaixilhado em vidro fusco.

Segunda divisão. - Leitura a córos, cada qual em seu compendio. Este trabalho poderá ser permutado com o do quarto tempo afim de diminuirem as vozes das duas primeiras divisões.

Terceira divisüo. - Tempo subdividido em dous quartos: no primeiro quarto, leitura a córos; no segundo, escripta dictada pelo professor ou copiada.

\section{Quarto tempo (uma hora).}

Primeira divisão. - Os alumnos escrevem a lapis sobre vidro fusco, ou copião em ardozias as lições estudadas (primeira meia hora). Correcção do trabalho pelos monitores, que tomaráó conțas do aproveitamento das turmas (segunda meia hora).

Segunda divisão. - Os alumnos escrevem sobre papel a lição estudada (primeira meia hcra). Os monitores ou adjuntos tomão as lições e corrigem o trabalho (segunda meia hora).

Terceira divisão. - Os alumnos desta divisão, formados em circulo ao redor da mesa do professor, darĩo contas do seu trabalho, começando pela leitura, seguindo-se a grammatica ou lição decorada; orthographia ou correcção de escripta, salvas em tudo as materias designadas para a lição do dia. Este trabalho será concluido em uma hora (modo simultaneo).

\section{Quinto tempo (meia hora).}

Terminação. - Oração final, chamada dos alumnos, e sahida.

Fonte: CASTILHO (1859). 
Apesar da aprovação do governo imperial, não havia um consenso referente às vantagens trazidas pelo seu método de ensino, como podemos perceber no trabalho de Almeida (1889),

Sérias objeções foram levantadas dentro da conferência pedagógica, contra o método Castilho, o qual, sob pretexto de simplificação, ensina a ler e escrever com ajuda de palavras que a ortografia excluiu, o que prejudica, mais tarde, o aluno e o impede de aprender a escrever corretamente (p.153).

Acerca das objeções nas Conferências Pedagógicas, Pires de Almeida referia-se, provavelmente, ao professor Manoel José Pereira Frazão que, após a exposição feita pelo professor Castilho sobre seu método de leitura, no encontro do ano de 1873, levantou algumas críticas a seu sistema. De acordo com o relatório da IGIPSC de 1872 (publicado em 1873):

O professor Frazão, não obstante concordar com o professor Castilho no ensino da leitura pelo methodo analytico, discorda desse professor no ponto em que se afasta da exatidão ortográfica no ensino da leitura e da caligrafia, parecendo-lhe isso muito prejudicial para o menino, que sempre se lembrará mais do primeiro modo por que aprendeu a escrever uma palavra, ainda que incorreto, do que o que lhe é posteriormente ensinado, posto que verdadeiro: acha também prejudicial a deslocação da ordem adotada nas letras do alfabeto, e o modo por que algumas delas são pronunciadas pelo professor Castilho, posto que dessa forma sejam adaptadas ao seu método (p.16).

No mesmo relatório consta a resposta de Castilho à questão levantada por seu colega de ofício, o professor Frazão:

O Sr. Castilho responde que não acha inconveniente em escolher, no ensino, palavras de fácil composição ortográfica, e que tenham de escrever-se segundo o som articulado: que usa da inversão na ordem natural do alfabeto só com o fim de facilitar ao menino o conhecimento das letras, fazendo-lhe conhecer primeiro as letras cuja forma é parecida e depois aquelas cujos sons tem analogia e mais se aproximam do modo por que soam na palavra, sendo certo que desse seu systema tem tirado resultados vantajosos (p.16).

O debate oral feito nas conferências torna-se um exemplo das disputas entre os professores/autores para a reafirmação de seus métodos e posições. Como nos alerta Schueler e Teixeira (2009), "as disputas entre os métodos, sobretudo no campo do ensino da leitura e escrita, revelavam as tensões que envolviam a consagração dos autores no mercado editorial, no momento em que se preconizava a 'nacionalização' dos livros, obras e materiais didáticos” (2009, p. 154).

O professor Castilho inegavelmente empenhou-se na defesa e divulgação de seu método. Como verificado na citação anterior, utilizou-se do espaço das conferências para defesa de suas ideias e igualmente da imprensa pedagógica do período ${ }^{13}$, ao enviar parte de suas obras para A Escola - Revista Brasileira de Educação e Ensino do Rio de Janeiro, na qual também atuou como redator, com o intuito de fazer propaganda. Castilho parece ter conseguido o espaço almejado, já que no ano de 1877, foi publicado na coluna "Imprensa", um artigo sobre o autor que, entre outras coisas, elogiava uma de suas obras, e o aconselhava a estendê-lo:

\footnotetext{
${ }^{13}$ Para uma análise da imprensa pedagógica da época no Rio de Janeiro, consultar Teixeira (2016).
} 
Não terminaremos estas linhas sem dizer o nosso colega Castilho que muito apreciamos a parte de seus Preliminares de Grammatica que começa ao artigo palavra e termina na pagina 80; e um trabalho muito útil e o Sr. Professor faria bem em lhe dar mais desenvolvimento e extensão, conservando a forma que tem de entretenimentos ou pequenas conferencias, para poderem servir não só a leitura dos alumnos, como de guia ás mães e pais que ensinam a seus filhos (1877, p.22).

Juntamente com o elogio ao trabalho de Castilho e com a recomendação de que o mesmo ampliasse seu trabalho, destaca-se no artigo a explícita recomendação de uso da obra, como "guia ás mães e pais que ensinam a seus filhos". Podemos perceber a opinião existente de que o livro poderia funcionar também como um objeto de formação e modelação da família, considerada uma forte aliada do governo imperial em seu projeto civilizatório.

Como parte de sua coleção "Escola Brasileira", Francisco Alves da Silva Castilho produziu o livro "O principio da sabedoria é o temor de Deos", publicado pela "Typographia Cinco de março", no ano de 1872. Com um total de 146 páginas, de formato in- $8^{\circ}$, capa verde e dura, sem o símbolo do Império. Apesar de não trazer tal símbolo, Castilho dedica sua obra, juntamente com as mães de família, ao "S. M. I. o Sr. D. Pedro II", o Imperador do Brasil, oferecendo-lhe as primeiras páginas de seu compêndio, com o intuito de apresentar sua "humilde offerenda", certo de que:

não se de dedignará de acolher ao menos a boa vontade de quem nada mais póde fazer do que manisfestar o desejo de ser útil, venho tambem por esta occasião apresentar-me com esta minha humilde offerenda que se V. M. I. a julgar capaz e digna do fim para que é destinado, poderei ter a satisfação de haver tomado parte de algum modo nesta contribuição. A minha offerta não é mais do que uma pequena serie de lições moraes para o ensino da mocidade dirigido pelas mães de famílias a quem a sabedoria de Deus proveu de todos os predicados de natura e verdadeira mestra da infância pelo império do amor e pela sensibilidades do coração juvenil. Ninguém melhor do que V. M. I. conhecerá a necessidade de formar-se a educação popular sobre os preceitos da boa moral e de uma philosophia ao alcance de todas as intelligencias afim de que os homens se conheção a si, comprehendão os seus deveres, e a vaidade de uma instrucção fartua os não desatine e empeiore ainda mais do que a própria ignorância. Não tenho a pretensão, Senhor, de haver composto um livro capaz de satisfazer esta necessidade, nem mesmo supponho haver falta de obras sabiamente elaboradas para esse fim, porém cada qual tem o seu methodo e o seu systema; e essa mesma differença no methodo das minhas lições, quando mais não valha, é uma circunstancia que poderá talvez influir favoravelmente nos resultados do ensino. Este é o pensamento que me esperança neste trabalho emprehendido sem outro incentivo mais que desejo de concorrer com a minha pequena quota parte para a grande obra da educação popular. Possa esta offerta alcançar o benevolo acolhimento de V. M. I. afim de que com o poderoso influxo de seu Augusto Nome venha a ser o meu livro recebido favoravelmente no seio domestico, e com a cooperação das mães de famílias ahi se desenvolva e fructifique o germem da doutrina que nessas pequenas paginas se encerra; pois julgo que os bons desejos do coração de V. M. I. no tocante á educação popular 
só se cumprirão cabalmente quando debaixo de todos os tectos puder brilhar a luz do ensino como o candieiro do pobre e o lampadario do rico. Portanto, Senhor, se V. M. I. se dignar de pôr os seus olhos sobre estas humildes paginas e julgar minha obra digna de sua honrosa acceitação, desejo que seja ella recebida com um fraco contingente de minha contribuição, consentindo V. M. I. que eu ajunte ao meu livro esta pagina mais em signal do alto favor e honra que por amor da instrucção solicita.

Escritas como as de Castilho, revestidas de palavras de humildade, submissão e exaltação da figura do destinatário, geralmente um superior, e no caso dos livros, candidato a mecenas, eram, como já assinalado, recorrentes nos documentos relativos à instrução no século XIX. Tal prática pode ser entendida como uma estratégia de seus remetentes para uma mais fácil aceitação de seus pedidos, na busca de um caminho mais curto para a realização de seus projetos. $\mathrm{O}$ emprego regular desta estratégia demonstra que os autores conheciam os dispositivos retóricos e os códigos de civilidade, recorrendo aos mesmos em defesa de seus interesses.

Esse livro seria formado, segundo o autor, "para despertar a reflexão da mocidade e firmar no seu espirito a ideia de Deus como base da moral e da religião". Juntamente com a dedicatória ao Imperador, traz um prólogo destinado aos "Paes, mães, educadores da mocidade", no qual apresenta um trecho da quarta carta da obra Da educação feita "pelo sábio Visconde de Almeida Garret"14, que era recomendada para os que tinham a seu cargo a educação da mocidade e para os que se ocupavam de assuntos pedagógicos. Castilho diz ter se inspirado na obra deste autor para a organização de seu livro. Também expõe um tópico destinado "Aos meninos", no qual apresenta um trecho do livro dos provérbios, pregando que o "Senhor" reservaria a salvação para os que fossem retos, assim como protegeria aos que caminhassem em simplicidade, sendo o "Senhor" responsável pela guarda das "veredas da justiça" e aquele que estaria de vigia "sobre os caminhos dos Santos".

A apresentação e apropriação de Castilho de outros textos, como os de Garret e os dos provérbios antes de iniciar seus capítulos, ou seja, antes de "fallar-vos com palavras minhas", pode ser entendido como uma tentativa de afirmação e legitimação de suas ideias, ao tentar mostrar ao leitor que elas são compatíveis com as de outros autores, provavelmente, já reconhecidos e aceitos pelo público em geral.

Por meio dos setenta capítulos é possível verificar que Castilho tratava de assuntos variados que abarcavam, entre outros tópicos, os atributos do homem (sentidos do corpo humano); virtudes e defeitos; elementos e fenômenos da natureza; e deveres familiares, sociais e para com a pátria. Contudo, demonstra preocupação de articulá-los ao tema da moral e da religião, como no caso em que aborda os sentidos. De acordo com o autor, por exemplo, com o ouvido, dever-se-ia ouvir e aprender a doutrina "dos que vos instruem", pois só assim, seria possível fazer "bom uso do vosso ouvido" e agradar a Deus. Ainda segundo Castilho, sentir, pensar e falar eram os mais sublimes dons que recebemos "do nosso creador" e pelos quais "nos avantajamos a todas as mais creaturas da terra".

Ao abordar temas referentes à natureza, que para ele "é o throno exterior da magnificência divina", assevera que aquele que a contempla e a estuda se elevaria gradualmente "ao throno interior do onipotente". Dessa forma, o referido autor tenta convencer seu leitor das "maravilhas" feitas por Deus, procurando comprovar sua bondade e a necessidade de se demonstrar "a gratidão que devemos ter por ele". Sobre os capítulos abordados, Castilho assinala:

\footnotetext{
${ }^{14}$ João Baptista da Silva Leitão, mais tarde Visconde de Almeida Garret, nasceu em 1799, na cidade de Lisboa, Portugal. Faleceu em 9 de dezembro de 1854. Foi um escritor e dramaturgo romântico, orador, ministro e secretário de Estado honorário português.
} 
Reconsiderando tudo quanto vos tenho dicto nas lições precedentes, podereis deduzir, meus jovens leitores, que o mundo em si mesmo é uma grande escola onde a natureza é a mestra que a providencia do Senhor Deos instituiu para ensinar o homem a conhecer o seu criador. Os sentidos e o pensamento são os meios com que a Divina Sabedoria habilitou o homem para contemplar e refletir sobre toda essa variedade de scenas que a natureza nos offerece como lições, umas vezes, amenas e aprazíveis como as risonhas manhans da primavera, outras vezes, severas e terríveis como o aspecto pavoroso da tempestade. E tudo deve despertar o vosso pensamento e fazer-vos reflectir sobre a fraqueza do ser humano perante o alto e tremendo poder que n'um só "faça-se" seria capaz de transformar o mundo e precipita-lo em um abismo de horrores.

Pelas palavras de Castilho, é possível perceber que uma das estratégias utilizadas por ele para persuadir seu leitor a seguir as recomendações de obediência à doutrina de Deus, era a de convencê-lo do "poder soberano" de Deus, almejando o temor de Deus. Não se constitui mera coincidência que sua obra se intitula, "O principio da sabedoria é o temor de Deos", evidência de sua proposta de doutrinação.

Castilho também se pronuncia acerca da instrução que, para ele, era uma necessidade do espírito assim como a alimentação era necessária para o sustento do corpo. Realiza uma comparação com a providência divina e argumenta que da mesma forma que Deus deixou sementes das plantas a serem cultivadas para nossa nutrição, igualmente deixou doutrinas que deveriam ser conservadas pelos homens, a serem passadas por meio do ensino a todas as gerações. Contudo, esta doutrina não poderia ser dada por qualquer um, mas sim com o auxílio de um guia que dirigisse a interpretação da mesma. Alerta ainda acerca do risco que correria quem se julgasse habilitado e desprezasse a "sabedoria dos interpretes da Igreja" nos pontos mais difíceis, pois poderia se transviar e se perder nos "labirintos do erro por não compreender o genuíno sentido do texto sagrado"

Para finalizar sua obra, Castilho se dirige à mãe de família que, para ele, seria a "verdadeira mestra instituída pela providencia de Deos" e a única capaz de levar o filho "somente pelo amor". Para o autor, sendo as mães as educadoras, haveria o bom acolhimento da doutrina e conselhos ficariam gravados no coração "com uma memória indelével do vosso amor". Porém, Castilho não deixa de alertar que mesmo tendo esse compromisso, as mães não poderiam deixar de mandar seus filhos à escola, para lá receberem a instrução do mestre. A responsabilidade materna ficaria limitada à parte moral da educação, sendo a instrução tarefa do mestre da escola. Como forma de convencê-las da importância de tal função, registra que sua parte seria na verdade a mais importante da educação por ser aquela que pode fazer os filhos serem bons e ainda torná-los felizes.

As ideias de Castilho estavam condizentes com a proposta de instrução do governo imperial e também da Igreja Católica, que buscavam controlar as práticas dos sujeitos, tendo a instrução como uma medida estratégica. Castilho sabia que para que seu livro fosse aprovado, deveria estar de acordo com as ideias dos representantes do poder, não por acaso, a semelhança de opiniões, como por exemplo, o alerta a respeito da necessidade de formação específica para o ensino da doutrina religiosa e a defesa da parceria entre escola e família, delegando às mães a função da educação moral e religiosa.

\section{Considerações finais}

No século XIX, observamos que os professores acionavam os recursos disponíveis para se afirmarem enquanto agentes da instrução e para participarem dos projetos de 
constituição de um modelo de escola e de professor. Compunham as estratégias utilizadas os diferentes modos de inserção dos professores na sociedade, como a participação em associações culturais, sociais e políticas. A atuação de Castilho na Sociedade Beneficente e Propagadora dos direitos dos cidadãos da freguesia de Campo Grande se deu valendo-se de sua condição de professor, imagem que foi acionada pela associação quando precisou defender sua idoneidade perante a sociedade.

Assim, pela trajetória de Castilho, foi possível perceber a relevância de se considerar nos debates acerca da escola e da docência do século XIX um conjunto de aspectos que remetem a atos como o de aderir, acomodar, resistir, traduzir e inventar, como sugere Escolano Benito (2011). Verbos enunciados a partir das atuações na escola, na imprensa, na autoria de obras, na invenção de métodos, na sociedade e na política.

Castilho, por um lado, apresentava ideias condizentes com a proposta de instrução do governo imperial, conforme assinalamos na produção de livros escolares e de métodos de ensino. Isso igualmente fica evidenciado na sua nomeação para o cargo de delegado da instrução na freguesia de Campo Grande, tornando-se dessa forma representante do Estado Imperial, em escala local, na fiscalização das escolas de sua freguesia.

Por outro lado, não se furtou a fazer severas críticas ao governo pela falta de progresso da instrução e por culpar os professores pelo atraso no ensino. Também se posicionou firmemente quando a escola pública em que lecionava foi ameaçada de fechamento, produzindo um tensionamento com o inspetor geral da instrução Eusébio de Queiroz, o mesmo que Castilho havia elogiado quando foi nomeado para o cargo.

Nesse sentido, o professor Castilho juntamente com outros professores e professoras de sua época retratam as diferentes formas de se exercer o magistério, de debater e disputar ideias educacionais, e de contribuir, por meio de suas trajetórias, atuações e experiências, na invenção da escola brasileira oitocentista.

\section{Referências}

A Escola - Revista Brasileira de educação e Ensino (1877-1878)

A Instrução Pública. Rio de Janeiro: Typographia Cinco de Março, 1872-75 e 1887-88.

ALBUQUERQUE, Suzana Lopes de. Métodos de ensino de leitura no Império brasileiro: António Feliciano de Castilho e Joseph Jacotot. Tese (Doutorado em Educação) - Faculdade de Educação, Universidade de São Paulo, São Paulo, 2019.

ALMEIDA, José Ricardo Pires. de. História da instrução pública no Brasil (1500-1889). Brasília: INEP/MEC, 1989.

BASTOS, Maria Helena Camara. O ensino mútuo no Brasil (1808 - 1827). In: BASTOS, Maria Helena Camara; FARIA FILHO, Luciano Mendes de (orgs.). A escola elementar no século XIX: o método monitorial/mútuo. Passo Fundo/RS: Ediupf, 1999.

BLAKE, Augusto V.A. Sacramento. Dicionário bibliographico brazileiro. Rio de Janeiro: Typographia Nacional, 1899.

BORGES, Angélica. A urdidura do magistério primário na Corte Imperial: um professor na trama de relações e agências. Tese (Doutorado em Educação) - Faculdade de Educação, Universidade de São Paulo, São Paulo, 2014. 
BORGES, Angélica. Ordem no ensino: a inspeção de professores primários na Capital do Império Brasileiro (1854-1865). Dissertação (Mestrado em educação) - Programa de PósGraduação em Educação, Universidade do Estado do Rio de Janeiro, Rio de Janeiro, 2008.

BORGES, Angélica; GONDRA, J. Política e arte de superar-se: um estudo acerca das Conferências Pedagógicas na Corte Imperial. In: Revista de Educação Pública. Cuiabá: EdUFMT, 2005, v.14, n.15.

CARVALHO, Silvia Aparecida Santos de. A cartilha Grammatica da Lingua Portuguesa com os mandamentos da Santa Madre Igreja (1539), o Compêndio de Doutrina Cristã de Luys de Granada (1559), o Compêndio de Doutrina Cristã na Lingua Portuguesa e Brasilica de Joam Phellipe Bettendorfe (1678) e o ensino da leitura no Brasil do século XVI. Linha Mestra, n.36, p.317-329, set./dez. 2018.

CASTILHO, Francisco Alves da Silva. Manual explicativo do methodo de leitura denominado Escola Brasileira. Rio de Janeiro: Typ. Universal de E. \& H Laemmert, 1859.

CASTILHO, Francisco Alves da Silva. O principio da sabedoria é o temor de Deos. Rio de Janeiro: Typographia Cinco de Março, 1872.

CORREIO DA TARDE, 28/01/1860.

CORREIO DA TARDE, 26/07/1860.

CORREIO MERCANTIL, 27/01/1861.

CORREIO MERCANTIL, 26/07/1860.

CUNHA, Marcus Vinicius da. A educação contra a família. In: LOPES, Eliane; VEIGA, Cynthia; FARIA FILHO, Luciano M. 500 anos de educação no Brasil. Belo Horizonte: Autêntica, 2000, p.447-468.

DIÁRIO DO RIO DE JANEIRO, 12/01/1861.

ESCOLANO BENITO, A. Arte y oficio de enseñar. In: P. CELADA PERANDONES (Ed.). Arte y oficio de enseñar. Dos siglos de perspectiva histórica (pp.17-26). El Burgo de Osma: Universidad de Valladolid - Ceince, 2011.

LEMOS, Daniel Cavalcanti de A. O Discurso da Ordem: A constituição do campo docente na Corte Imperial. Dissertação (Mestrado em educação) - Faculdade de Educação da Universidade do Estado do Rio de Janeiro, Rio de Janeiro, 2006.

MARTINEZ, Alessandra Frota. Educar e instruir: a instrução pública na Corte Imperial (18701889). Niterói: UFF, 1998. Dissertação de Mestrado.

MATTOS, Hebe Maria. Escravidão e cidadania no Brasil monárquico. Rio de Janeiro: Jorge Zahar Editor, 2000.

MATTOS, Ilmar Rohloff. O Tempo Saquarema. Rio de Janeiro: Access Editora, 2004. 
MUNHOZ, Fabiana Garcia; BORGES, Angélica. Apresentação do dossiê: Magistério Oitocentista: contribuições da história da educação na problematização de questões de gênero, etnia e protagonismo docente. Revista Brasileira de História da Educação, 2018, vol.18.

NÓVOA, Antonio. O processo histórico de profissionalização do professorado. In: NÓVOA, A. (Org.). Profissão professor. Porto: Porto Editora, 1991, p.9-32.

O APÓSTOLO, 13/02/1870.

O APÓSTOLO, 27/02/1870.

RELATÓRIO DA INSPETORIA GERAL DE INSTRUÇÃO PRIMÁRIA E SECUNDÁRIA DA CORTE de 1855, anexo ao Relatório do Ministro do Império de 1855.

RELATÓRIO DA INSPETORIA GERAL DE INSTRUÇÃO PRIMÁRIA E SECUNDÁRIA DA CORTE de 1857, anexo ao Relatório do Ministro do Império de 1857.

RELATÓRIO DA INSPETORIA GERAL DE INSTRUÇÃO PRIMÁRIA E SECUNDÁRIA DA CORTE de 1872, anexo ao Relatório do Ministro do Império de 1872, publicado em 1873.

RELATÓRIO DA INSPETORIA GERAL DE INSTRUÇÃO PRIMÁRIA E SECUNDÁRIA DA CORTE de 1877, anexo ao Relatório do Ministro do Império de 1877.

RELATÓRIO DA INSPETORIA GERAL DE INSTRUÇÃO PRIMÁRIA E SECUNDÁRIA DA CORTE de 1883, anexo ao Relatório do Ministro do Império de 1883.

ROQUETTE, J.I. Código do Bom Tom ou Regras da civilidade e do bem viver no século XIX. São Paulo: Companhia das letras, 1997.

SCHUELER, Alessandra F. Martinez de; SILVA, Josele Teixeira da. Experiências profissionais e produção intelectual de professores primários na Corte imperial (1860-1890). In: VI Congresso Luso-Brasileiro de História da Educação, 2006, Uberlândia. Anais do VI Congresso Luso-Brasileiro de História da Educação. Uberlândia, 2006. p. 6122-6133.

SCHUELER, Alessandra F. Martinez de. Experiências profissionais e produção intelectual de professores primários na corte imperial (1860 - 1889). Projeto de Pesquisa, Rio de Janeiro, UERJ, 2005a.

SCHUELER, Alessandra F. Martinez de. Representações da docência na imprensa pedagógica na Corte Imperial (1871- 1889). Educação e Pesquisa, São Paulo, v.31, n.3, set./dez. 2005b, p.379-390. https://doi.org/10.1590/S1517-97022005000300004

SCHUELER, Alessandra F. Martinez de. Culturas escolares e experiências docentes na cidade do Rio de Janeiro (1854-1889). Tese (Doutorado em educação) - Faculdade de Educação da UFF, Niterói, 2002.

SCHUELER, Alessandra F. Martinez de; TEIXEIRA, Giselle Baptista. Livros para a escola primária carioca no século XIX: produção, circulação e adoção de textos escolares de professores. Revista Brasileira de História da Educação, n 20, p. 137-164, maio/ago. 2009. 
TEIXEIRA, Giselle. A imprensa pedagógica no Rio de Janeiro: os jornais e as revistas como agentes construtores da escola (1870 - 1919). Tese (Doutorado em educação) - Faculdade de Educação da UFF, Niterói, 2016.

TEIXEIRA, Giselle. O Grande Mestre da Escola: Os livros de leitura para a Escola Primária da Capital do Império Brasileiro. Dissertação (Mestrado em Educação) - Faculdade de Educação da UERJ, Rio de Janeiro, 2008.

THOMPSON, Edward. Costumes em comum - Estudos sobre a cultura popular tradicional. São Paulo: Companhia das letras, 2005.

VIDAL, Diana Gonçalves. A docência como uma experiência coletiva: questões para debate. In: DALBEN, Ângela; DINIZ, Júlio; LEAL, Leiva e SANTOS, Lucíola. (Orgs.). Convergências e tensões no campo da formação e do trabalho docente: didática, formação de professores e trabalho docente. Belo Horizonte: Autêntica, 2010, p. 711-731.

VILLELA, Heloísa. Da Palmatória a Lanterna Mágica: A Escola Normal da Província do Rio de Janeiro entre o artesanato e a formação Profissional (1868-1876). Tese de Doutorado, Faculdade de Educação, Universidade de São Paulo, 2002.

VILLELA, Heloisa. O mestre-escola e a professora. In: LOPES, Eliane; VEIGA, Cynthia; FARIA FILHO, Luciano M. 500 anos de educação no Brasil. Belo Horizonte: Autêntica, 2000, p. 95-134. 